\title{
COMMON FIXED POINTS OF TWO NONEXPANSIVE MAPPINGS BY A MODIFIED FASTER ITERATION SCHEME
}

\author{
Safeer Hussain Khan and Jong Kyu Kim
}

\begin{abstract}
We introduce an iteration scheme for approximating common fixed points of two mappings. On one hand, it extends a scheme due to Agarwal et al. [2] to the case of two mappings while on the other hand, it is faster than both the Ishikawa type scheme and the one studied by Yao and Chen [18] for the purpose in some sense. Using this scheme, we prove some weak and strong convergence results for approximating common fixed points of two nonexpansive self mappings. We also outline the proofs of these results to the case of nonexpansive nonself mappings.
\end{abstract}

\section{Introduction}

Throughout this paper, $\mathbb{N}$ denotes the set of all positive integers. Let $E$ be a real Banach space and $C$ a nonempty subset of $E$. A mapping $T: C \rightarrow C$ is called nonexpansive self mapping if

$$
\|T x-T y\| \leq\|x-y\|
$$

for all $x, y \in C$. For the sake of simplicity, we call nonexpansive self mapping as nonexpansive mapping. A mapping $T: C \rightarrow C$ is called contraction if there is a $k \in(0,1)$ such that

$$
\|T x-T y\| \leq k\|x-y\|
$$

for all $x, y \in C$.

We know that Picard and Mann [12] iteration schemes for a mapping $T$ : $C \rightarrow C$ are defined by

$$
\left\{\begin{array}{l}
x_{1}=x \in C, \\
x_{n+1}=T x_{n}, n \in \mathbb{N}
\end{array}\right.
$$

Received March 20, 2009; Revised February 19, 2010. 2000 Mathematics Subject Classification. 47H09, 47H10.

Key words and phrases. iteration scheme, nonexpansive self mapping, nonexpansive nonself mapping, rate of convergence, common fixed point, the condition $\left(A^{\prime}\right)$, weak and strong convergence. 
and

$$
\left\{\begin{array}{l}
x_{1}=x \in C, \\
x_{n+1}=\left(1-\alpha_{n}\right) x_{n}+\alpha_{n} T x_{n}, \quad n \in \mathbb{N}
\end{array}\right.
$$

respectively, where $\left\{\alpha_{n}\right\}$ is in $(0,1)$. It is well-known that Picard iteration scheme converges for contractions but may not converge for nonexpansive mappings whereas Mann iteration scheme converges for nonexpansive mappings as well. Agarwal, O'Regan, and Sahu [2] posed the question:

Is there any scheme for contraction mappings which converges at a rate similar to Picard iteration scheme?

As an answer they introduced the following iteration scheme:

$$
\left\{\begin{array}{l}
x_{1}=x \in C, \\
x_{n+1}=\left(1-\alpha_{n}\right) T x_{n}+\alpha_{n} T y_{n}, \\
y_{n}=\left(1-\beta_{n}\right) x_{n}+\beta_{n} T x_{n}, \quad n \in \mathbb{N},
\end{array}\right.
$$

where $\left\{\alpha_{n}\right\}$ and $\left\{\beta_{n}\right\}$ are in $(0,1)$. They proved that

$$
\begin{aligned}
\left\|x_{n+1}-p\right\| & \leq k\left\|x_{n}-p\right\| \\
\left\|x_{n+1}-p\right\| & \leq\left(1-(1-k) \alpha_{n}\right)\left\|x_{n}-p\right\| \text { and } \\
\left\|x_{n+1}-p\right\| & \leq k\left[1-(1-k) \alpha_{n} \beta_{n}\right]\left\|x_{n}-p\right\|
\end{aligned}
$$

hold for $(1.1),(1.2)$ and (1.3) respectively, see Proposition 3.1 [2]. They concluded from this that their scheme converges at a rate similar to that of Picard iteration scheme and faster than the Mann iteration scheme for contraction mappings and this provided a positive answer to the above question. It should be noted that, of course, the comparison between the schemes is difficult because they depend on the choice of the sequences $\left\{\alpha_{n}\right\}$ and $\left\{\beta_{n}\right\}$.

On the other hand, let us state without error terms the iteration scheme studied by Yao and Chen [18] for common fixed points of two mappings:

$$
\left\{\begin{array}{l}
x_{1}=x \in C, \\
x_{n+1}=\alpha_{n} x_{n}+\beta_{n} T x_{n}+\gamma_{n} S x_{n}, n \in \mathbb{N},
\end{array}\right.
$$

where $\left\{\alpha_{n}\right\}$ and $\left\{\beta_{n}\right\}$ are in $[0,1]$ and $\alpha_{n}+\beta_{n}+\gamma_{n}=1$. We note that (1.4) reduces to Mann iteration scheme (1.2) when $T=I$ or $S=I$.

The following Ishikawa type iteration scheme has been studied by various authors for common fixed points of two mappings, see for example [5], [9], [10], $[15]$ and $[17]$.

$$
\left\{\begin{array}{l}
x_{1}=x \in C, \\
x_{n+1}=\left(1-\alpha_{n}\right) x_{n}+\alpha_{n} S y_{n}, \\
y_{n}=\left(1-\beta_{n}\right) x_{n}+\beta_{n} T x_{n}, \quad n \in \mathbb{N},
\end{array}\right.
$$

where $\left\{\alpha_{n}\right\}$ and $\left\{\beta_{n}\right\}$ are in $[0,1]$. This scheme also reduces to Mann iteration scheme (1.2) when $T=I$ or $S=I$. 
Analogous to the question posed by Agarwal, O`Regan and Sahu, we ask:

Is there any scheme to compute common fixed points for two contraction mappings which converges at a rate similar to Picard scheme and faster than its counter parts?

As an answer, we introduce the following iteration scheme to compute the common fixed points of two mappings.

$$
\left\{\begin{array}{l}
x_{1}=x \in C, \\
x_{n+1}=\left(1-\alpha_{n}\right) T x_{n}+\alpha_{n} S y_{n}, \\
y_{n}=\left(1-\beta_{n}\right) x_{n}+\beta_{n} T x_{n}, \quad n \in \mathbb{N},
\end{array}\right.
$$

where $\left\{\alpha_{n}\right\}$ and $\left\{\beta_{n}\right\}$ are in $(0,1)$.

Similar as for the first three iteration schemes, one can show that $\| x_{n+1}-$ $p\left\|\leq k\left(1-\alpha_{n} \beta_{n}(1-k)\right)\right\| x_{n}-p \|$ holds for $(1.6),\left\|x_{n+1}-p\right\| \leq k\left(1-\left(1-\alpha_{n}\right)(1-\right.$ $k))\left\|x_{n}-p\right\|$ holds for $(1.4)$, and $\left\|x_{n+1}-p\right\| \leq\left(1-\alpha_{n} \beta_{n} k(1-k)\right)\left\|x_{n}-p\right\|$ holds for (1.5). One cannot know if these estimates are sharp but following [2], these estimates suggest that our scheme also converges at a rate similar to that of Picard (1.1) and Agarwal et al. (1.3) and faster than (1.2), (1.4) and (1.5) for contraction mappings and this provides a positive answer to the above question.

We see that (1.6) is independent of both (1.4) and (1.5). It is also to be noted that (1.6) reduces to (1.3) for $S=T$ and to (1.2) when $T=I$ or $S=I$ (cf. [1]). Note also that neither of (1.4) and (1.5) reduce to (1.3) nor conversely. It means that results proved by (1.4) and (1.5) do not include the ones proved by (1.3), leave alone (1.6).

Note that (1.3) does not reduce to (1.2) but (1.6) does. It means that the results proved by using (1.6) not only contain the corresponding results proved by (1.3) but also cover the left over ones for (1.2).

Our purpose in the rest of the paper is to use the scheme (1.6) to prove some weak and strong convergence results for approximating common fixed points of two nonexpansive mappings.

Let us now gather some pre-requisites . Let $S=\{x \in E:\|x\|=1\}$ and $E^{*}$ the dual of $E$. The space $E$ has : (i) Gâteaux differentiable norm if

$$
\lim _{t \rightarrow 0} \frac{\|x+t y\|-\|x\|}{t}
$$

exists for each $x$ and $y$ in $S$; (ii) Fréchet differentiable norm (see e.g. [16]) if for each $x$ in $S$, the above limit exists and is attained uniformly for $y$ in $S$ and in this case, it is also well-known that

$$
\langle h, J(x)\rangle+\frac{1}{2}\|x\|^{2} \leq \frac{1}{2}\|x+h\|^{2} \leq\langle h, J(x)\rangle+\frac{1}{2}\|x\|^{2}+b(\|h\|)
$$

for all $x, h$ in $E$, where $J$ is the Fréchet derivative of the functional $\frac{1}{2}\|\cdot\|^{2}$ at $x \in X,\langle\cdot, \cdot\rangle$ is the dual pairing between $E$ and $E^{*}$, and $b$ is an increasing function defined on $[0, \infty)$ such that $\lim _{t \downarrow 0} \frac{b(t)}{t}=0$; (iii) Opial's condition [13] if for any sequence $\left\{x_{n}\right\}$ in $E, x_{n} \rightarrow x$ implies that $\lim _{\sup _{n \rightarrow \infty}}\left\|x_{n}-x\right\|<$ 
$\lim \sup _{n \rightarrow \infty}\left\|x_{n}-y\right\|$ for all $y \in E$ with $y \neq x$ and (iv) Kadec-Klee property if for every sequence $\left\{x_{n}\right\}$ in $E, x_{n} \rightarrow x$ and $\left\|x_{n}\right\| \rightarrow\|x\|$ together imply $x_{n} \rightarrow x$ as $n \rightarrow \infty$.

Let $\delta$ be the modulus of uniform convexity. Recall that if $E$ is a uniformly convex Banach space, then (see e.g. [4])

$$
\|t x+(1-t) y\| \leq 1-2 t(1-t) \delta(\|x-y\|)
$$

for all $t \in[0,1]$ and for all $x, y \in E$ such that $\|x\| \leq 1,\|y\| \leq 1$.

A mapping $T: C \rightarrow E$ is demiclosed at $y \in E$ if for each sequence $\left\{x_{n}\right\}$ in $C$ and each $x \in E, x_{n} \rightarrow x$ and $T x_{n} \rightarrow y$ imply that $x \in C$ and $T x=y$ [11].

Lemma 1.1 ([14]). Let $E$ be a uniformly convex Banach space and $0<p \leq$ $t_{n} \leq q<1$ for all $n \in \mathbb{N}$. Suppose that $\left\{x_{n}\right\}$ and $\left\{y_{n}\right\}$ are two sequences of $E$ such that

$$
\begin{aligned}
& \limsup _{n \rightarrow \infty}\left\|x_{n}\right\| \leq r, \\
& \limsup _{n \rightarrow \infty}\left\|y_{n}\right\| \leq r \text { and } \\
& \lim _{n \rightarrow \infty}\left\|t_{n} x_{n}+\left(1-t_{n}\right) y_{n}\right\|=r
\end{aligned}
$$

hold for some $r \geq 0$. Then $\lim _{n \rightarrow \infty}\left\|x_{n}-y_{n}\right\|=0$.

Lemma $1.2([3])$. Let $E$ be a uniformly convex Banach space satisfying Opial's condition and let $C$ be a nonempty closed convex subset of $E$. Let $T: C \rightarrow E$ be a nonexpansive mapping. Then $I-T$ is demiclosed with respect to zero.

Lemma $1.3([7,8])$. Let $E$ be a reflexive Banach space such that $E^{*}$ has the Kadec-Klee property. Let $\left\{x_{n}\right\}$ be a bounded sequence in $E$ and $x^{*}, y^{*} \in W=$ $\omega_{w}\left(x_{n}\right)$ (weak limit set of $\left.\left\{x_{n}\right\}\right)$. Suppose $\lim _{n \rightarrow \infty}\left\|t x_{n}+(1-t) x^{*}-y^{*}\right\|$ exists for all $t \in[0,1]$. Then $x^{*}=y^{*}$.

Lemma 1.4 ([4]). Let $C$ be a nonempty bounded closed convex subset of a uniformly convex Banach space and $T: C \rightarrow E$ be a nonexpansive mapping. Then there is a strictly increasing and continuous convex function $g:[0, \infty) \rightarrow$ $[0, \infty)$ with $g(0)=0$ such that

$$
g(\|T(t x+(1-t) y)-(t T x+(1-t) T y \|) \leq\| x-y\|-\| T x-T y \|
$$

for all $x, y \in C$ and $t \in[0,1]$.

\section{Convergence theorems for nonexpansive self mappings}

Now we prove weak and strong convergence results by starting with the following. In the sequel, $F$ denotes the set of common fixed points of the mappings $T$ and $S$.

Theorem 2.1. Let $C$ be a nonempty closed convex subset of a uniformly convex Banach space $E$. Let $T$ and $S$ be two nonexpansive self mappings of $C$. Let $\left\{x_{n}\right\}$ be defined by the iteration scheme (1.6) where $\left\{\alpha_{n}\right\},\left\{\beta_{n}\right\}$ are in $[\varepsilon, 1-\varepsilon]$ 
for all $n \in \mathbb{N}$ and for some $\varepsilon$ in $(0,1)$. If $F \neq \varnothing$, then $\lim \left\|x_{n}-q\right\|$ exists and $\lim _{n \rightarrow \infty}\left\|x_{n}-T x_{n}\right\|=0=\lim _{n \rightarrow \infty}\left\|x_{n}-S x_{n}\right\|$.

Proof. Let $q \in F$. Then

$$
\begin{aligned}
\left\|x_{n+1}-q\right\| & =\left\|\left(1-\alpha_{n}\right) T x_{n}+\alpha_{n} S y_{n}-q\right\| \\
& \leq\left(1-\alpha_{n}\right)\left\|T x_{n}-q\right\|+\alpha_{n}\left\|S y_{n}-q\right\| \\
& \leq\left(1-\alpha_{n}\right)\left\|x_{n}-q\right\|+\alpha_{n}\left\|y_{n}-q\right\| \\
& \leq\left(1-\alpha_{n}\right)\left\|x_{n}-q\right\|+\alpha_{n}\left(1-\beta_{n}\right)\left\|x_{n}-q\right\|+\alpha_{n} \beta_{n}\left\|T x_{n}-q\right\| \\
& \leq\left(1-\alpha_{n}\right)\left\|x_{n}-q\right\|+\alpha_{n}\left(1-\beta_{n}\right)\left\|x_{n}-q\right\|+\alpha_{n} \beta_{n}\left\|x_{n}-q\right\| \\
& =\left\|x_{n}-q\right\| .
\end{aligned}
$$

Hence $\lim \left\|x_{n}-q\right\|$ exists for any $q \in F$. Say it $c$.

Now

$$
\begin{aligned}
\left\|y_{n}-q\right\| & =\left\|\beta_{n} T x_{n}+\left(1-\beta_{n}\right) x_{n}-q\right\| \\
& =\left\|\beta_{n}\left(T x_{n}-q\right)+\left(1-\beta_{n}\right)\left(x_{n}-q\right)\right\| \\
& \leq\left\|x_{n}-q\right\|
\end{aligned}
$$

implies that

$$
\limsup _{n \rightarrow \infty}\left\|y_{n}-q\right\| \leq c .
$$

Also from

$$
\left\|T x_{n}-q\right\| \leq\left\|x_{n}-q\right\|,
$$

we get

$$
\limsup _{n \rightarrow \infty}\left\|T x_{n}-q\right\| \leq c .
$$

Next,

gives by (2.1) that

$$
\left\|S y_{n}-q\right\| \leq\left\|y_{n}-q\right\|
$$

$$
\limsup _{n \rightarrow \infty}\left\|S y_{n}-q\right\| \leq c .
$$

Moreover,

$$
c=\lim _{n \rightarrow \infty}\left\|x_{n+1}-q\right\|=\lim _{n \rightarrow \infty}\left\|\left(1-\alpha_{n}\right)\left(T x_{n}-q\right)+\alpha_{n}\left(S y_{n}-q\right)\right\|
$$

gives by Lemma 1.1,

$$
\lim _{n \rightarrow \infty}\left\|T x_{n}-S y_{n}\right\|=0
$$

Now

$$
\begin{aligned}
\left\|x_{n+1}-q\right\| & =\left\|\left(1-\alpha_{n}\right) T x_{n}+\alpha_{n} S y_{n}-q\right\| \\
& =\left\|\left(T x_{n}-q\right)+\alpha_{n}\left(S y_{n}-T x_{n}\right)\right\| \\
& \leq\left\|T x_{n}-q\right\|+\alpha_{n}\left\|T x_{n}-S y_{n}\right\|
\end{aligned}
$$


yields that

so that (2.2) gives

$$
c \leq \liminf _{n \rightarrow \infty}\left\|T x_{n}-q\right\|
$$

$$
\lim _{n \rightarrow \infty}\left\|T x_{n}-q\right\|=c .
$$

In turn,

$$
\begin{aligned}
\left\|T x_{n}-q\right\| & \leq\left\|T x_{n}-S y_{n}\right\|+\left\|S y_{n}-q\right\| \\
& \leq\left\|T x_{n}-S y_{n}\right\|+\left\|y_{n}-q\right\|
\end{aligned}
$$

implies

$$
c \leq \liminf _{n \rightarrow \infty}\left\|y_{n}-q\right\| .
$$

By (2.1) and (2.5), we obtain

$$
\lim _{n \rightarrow \infty}\left\|y_{n}-q\right\|=c .
$$

Thus $c=\lim _{n \rightarrow \infty}\left\|y_{n}-q\right\|=\lim _{n \rightarrow \infty}\left\|\left(1-\beta_{n}\right)\left(x_{n}-q\right)+\beta_{n}\left(T x_{n}-q\right)\right\|$ gives by Lemma 1.1 that

$$
\lim _{n \rightarrow \infty}\left\|T x_{n}-x_{n}\right\|=0 .
$$

Now

implies by (2.7) that

$$
\left\|y_{n}-x_{n}\right\|=\beta_{n}\left\|T x_{n}-x_{n}\right\|
$$

$$
\lim _{n \rightarrow \infty}\left\|y_{n}-x_{n}\right\|=0
$$

Using (2.3), (2.7) and (2.8), we have

$$
\begin{aligned}
\left\|x_{n}-S x_{n}\right\| & \leq\left\|x_{n}-T x_{n}\right\|+\left\|T x_{n}-S y_{n}\right\|+\left\|S y_{n}-S x_{n}\right\| \\
& \leq\left\|x_{n}-T x_{n}\right\|+\left\|T x_{n}-S y_{n}\right\|+\left\|y_{n}-x_{n}\right\|
\end{aligned}
$$

and so

$$
\lim _{n \rightarrow \infty}\left\|x_{n}-S x_{n}\right\|=0 .
$$

Lemma 2.2. For any $p_{1}, p_{2} \in F, \lim _{n \rightarrow \infty}\left\|t x_{n}+(1-t) p_{1}-p_{2}\right\|$ exists for all $t \in[0,1]$ under the conditions of Theorem 2.1.

Proof. By Theorem 2.1, $\lim _{n \rightarrow \infty}\left\|x_{n}-p\right\|$ exists for all $p \in F$ and therefore $\left\{x_{n}\right\}$ is bounded. Thus there exists a real number $r>0$ such that $\left\{x_{n}\right\} \subseteq$ $D \equiv \overline{B_{r}(0)} \cap C$, so that $D$ is a closed convex nonempty subset of $C$. Define $a_{n}: D \rightarrow D$ as

$$
a_{n}(t)=\left\|t x_{n}+(1-t) p_{1}-p_{2}\right\|
$$

for all $t \in[0,1]$. Then both $\lim _{n \rightarrow \infty} a_{n}(0)=\left\|p_{1}-p_{2}\right\|$ and $\lim _{n \rightarrow \infty} a_{n}(1)=$ $\lim _{n \rightarrow \infty}\left\|x_{n}-p_{2}\right\|$ exist. Let $t \in(0,1)$. For each $n \in \mathbb{N}$, define a mapping $W_{n}: D \rightarrow D$ by

$$
W_{n} x=\left(1-\alpha_{n}\right) T x+\alpha_{n} S\left(\left(1-\beta_{n}\right) x+\beta_{n} T x\right), \quad \forall x \in D .
$$


It is easy to verify that

$$
\left\|W_{n} x-W_{n} y\right\| \leq\|x-y\|, \quad \forall x, y \in D .
$$

Set

$$
R_{n, m}=W_{n+m-1} W_{n+m-2} \cdots W_{n}
$$

and

$$
b_{n, m}=\left\|R_{n, m}\left(t x_{n}+(1-t) p_{1}\right)-\left(t R_{n, m} x_{n}+(1-t) p_{1}\right)\right\|, \quad \forall n, m \in \mathbb{N} .
$$

Then it follows that $\left\|R_{n, m} x-R_{n, m} y\right\| \leq\|x-y\|$ for all $x, y \in D, R_{n, m} x_{n}=$ $x_{n+m}$ and $R_{n, m} p=p$ for all $p \in F$. By Lemma 1.4, there exists a strictly increasing continuous function $g:[0, \infty) \rightarrow[0, \infty)$ with $g(0)=0$ such that

$$
\begin{aligned}
g\left(b_{n, m}\right) & \leq\left\|x_{n}-p_{1}\right\|-\left\|R_{n, m} x_{n}-R_{n, m} p_{1}\right\| \\
& =\left\|x_{n}-p_{1}\right\|-\left\|x_{n+m}-p_{1}\right\| .
\end{aligned}
$$

Since $\lim _{n \rightarrow \infty}\left\|x_{n}-p\right\|$ exists for all $p \in F$, we get

$$
\lim _{n \rightarrow \infty} \limsup _{m \rightarrow \infty} g\left(b_{n, m}\right)=0
$$

and consequently,

$$
\lim _{n \rightarrow \infty} \limsup _{m \rightarrow \infty} b_{n, m}=0 .
$$

Finally, from the inequality

$$
\begin{aligned}
a_{n+m}(t) & =\left\|t x_{n+m}+(1-t) p_{1}-p_{2}\right\| \\
& \leq b_{n, m}+\left\|R_{n, m}\left(t x_{n}+(1-t) p_{1}\right)-p_{2}\right\| \\
& =b_{n, m}+\left\|R_{n, m}\left(t x_{n}+(1-t) p_{1}\right)-R_{n, m} p_{2}\right\| \\
& \left.\leq b_{n, m}+\| t x_{n}+(1-t) p_{1}\right)-p_{2} \| \\
& =b_{n, m}+a_{n}(t),
\end{aligned}
$$

it follows that

$$
\limsup _{m \rightarrow \infty} a_{n+m}(t) \leq \limsup _{m \rightarrow \infty} b_{n, m}+a_{n}(t) .
$$

Since $\lim _{n \rightarrow \infty} \lim \sup _{m \rightarrow \infty} b_{n, m}=0$, we get

$$
\limsup _{m \rightarrow \infty} a_{m}(t) \leq \liminf _{n \rightarrow \infty} a_{n}(t) .
$$

Hence $\lim _{n \rightarrow \infty}\left\|t x_{n}+(1-t) p_{1}-p_{2}\right\|$ exists for all $t \in[0,1]$.

Lemma 2.3. Assume that the conditions of Theorem 2.1 are satisfied. Then, for any $p_{1}, p_{2} \in F, \lim _{n \rightarrow \infty}\left\langle x_{n}, J\left(p_{1}-p_{2}\right)\right\rangle$ exists; in particular,

$$
\left\langle p-q, J\left(p_{1}-p_{2}\right)\right\rangle=0
$$

for all $p, q \in \omega_{w}\left(x_{n}\right)$, the set of all weak limits of $\left\{x_{n}\right\}$. 
Proof. Let $t \in[0,1]$. Take $x=p_{1}-p_{2}$ with $p_{1} \neq p_{2}$ and $h=t\left(x_{n}-p_{1}\right)$ in the inequality (1.7) to get:

$$
\begin{aligned}
& \frac{1}{2}\left\|p_{1}-p_{2}\right\|^{2}+t\left\langle x_{n}-p_{1}, J\left(p_{1}-p_{2}\right)\right\rangle \\
\leq & \frac{1}{2}\left\|t x_{n}+(1-t) p_{1}-p_{2}\right\|^{2} \\
\leq & \frac{1}{2}\left\|p_{1}-p_{2}\right\|^{2}+t\left\langle x_{n}-p_{1}, J\left(p_{1}-p_{2}\right)\right\rangle+b\left(t\left\|x_{n}-p_{1}\right\|\right) .
\end{aligned}
$$

As $\sup _{n \geq 1}\left\|x_{n}-p_{1}\right\| \leq M^{\prime}$ for some $M^{\prime}>0$, it follows that

$$
\begin{aligned}
& \frac{1}{2}\left\|p_{1}-p_{2}\right\|^{2}+t \limsup _{n \rightarrow \infty}\left\langle x_{n}-p_{1}, J\left(p_{1}-p_{2}\right)\right\rangle \\
\leq & \frac{1}{2} \lim _{n \rightarrow \infty}\left\|t x_{n}+(1-t) p_{1}-p_{2}\right\|^{2} \\
\leq & \frac{1}{2}\left\|p_{1}-p_{2}\right\|^{2}+b\left(t M^{\prime}\right)+t \liminf _{n \rightarrow \infty}\left\langle x_{n}-p_{1}, J\left(p_{1}-p_{2}\right)\right\rangle .
\end{aligned}
$$

That is,

$$
\limsup _{n \rightarrow \infty}\left\langle x_{n}-p_{1}, J\left(p_{1}-p_{2}\right)\right\rangle \leq \liminf _{n \rightarrow \infty}\left\langle x_{n}-p_{1}, J\left(p_{1}-p_{2}\right)\right\rangle+\frac{b\left(t M^{\prime}\right)}{t M^{\prime}} M^{\prime} .
$$

If $t \rightarrow 0$, then $\lim _{n \rightarrow \infty}\left\langle x_{n}-p_{1}, J\left(p_{1}-p_{2}\right)\right\rangle$ exists for all $p_{1}, p_{2} \in F$; in particular, we have $\left\langle p-q, J\left(p_{1}-p_{2}\right)\right\rangle=0$ for all $p, q \in \omega_{w}\left(x_{n}\right)$.

We now give our weak convergence theorem.

Theorem 2.4. Let $E$ be a uniformly convex Banach space and let $C, T, S$ and $\left\{x_{n}\right\}$ be as in Theorem 2.1. Assume that (a) E satisfies Opial's condition, (b) $E$ has a Fréchet differentiable norm or (c) dual $E^{*}$ of E satisfies Kadec-Klee property. If $F \neq \varnothing$, then $\left\{x_{n}\right\}$ converges weakly to a point of $F$.

Proof. Let $p \in F$. Then $\lim _{n \rightarrow \infty}\left\|x_{n}-p\right\|$ exists as proved in Theorem 2.1. We prove that $\left\{x_{n}\right\}$ has a unique weak subsequential limit in $F$. Let $u$ and $v$ be weak limits of the subsequences $\left\{x_{n_{i}}\right\}$ and $\left\{x_{n_{j}}\right\}$ of $\left\{x_{n}\right\}$, respectively. By Theorem 2.1, $\lim _{n \rightarrow \infty}\left\|x_{n}-T x_{n}\right\|=0$ and $I-T$ is demiclosed with respect to zero by Lemma 1.2, therefore we obtain $T u=u$. Similarly, $S u=u$. Again in the same fashion, we can prove that $v \in F$. Next, we prove the uniqueness. To this end, first assume that (a) is true. If $u$ and $v$ are distinct, then by Opial's condition,

$$
\begin{aligned}
\lim _{n \rightarrow \infty}\left\|x_{n}-u\right\| & =\lim _{n_{i} \rightarrow \infty}\left\|x_{n_{i}}-u\right\|<\lim _{n_{i} \rightarrow \infty}\left\|x_{n_{i}}-v\right\|=\lim _{n \rightarrow \infty}\left\|x_{n}-v\right\| \\
& =\lim _{n_{j} \rightarrow \infty}\left\|x_{n_{j}}-v\right\|<\lim _{n_{j} \rightarrow \infty}\left\|x_{n_{j}}-u\right\|=\lim _{n \rightarrow \infty}\left\|x_{n}-u\right\| .
\end{aligned}
$$

This is a contradiction so $u=v$.

Next, assume (b). By Lemma 2.3, $\left\langle p-q, J\left(p_{1}-p_{2}\right)\right\rangle=0$ for all $p, q \in$ $\omega_{w}\left(x_{n}\right)$. Therefore $\|u-v\|^{2}=\langle u-v, J(u-v)\rangle=0$ implies $u=v$. 
Finally, assume that (c) is true. Since $\lim _{n \rightarrow \infty}\left\|t x_{n}+(1-t) u-v\right\|$ exists for all $t \in[0,1]$ by Lemma 2.2, therefore $u=v$ by Lemma 1.3. Consequently, $\left\{x_{n}\right\}$ converges weakly to a point of $F$ and this completes the proof.

Two mappings $S, T: C \rightarrow C$, where $C$ is a subset of a normed space $E$, are said to satisfy the condition $\left(A^{\prime}\right)[6]$ if there exists a nondecreasing function $f:[0, \infty) \rightarrow[0, \infty)$ with $f(0)=0, f(r)>0$ for all $r \in(0, \infty)$ such that either $\|x-S x\| \geq f(D(x, F))$ or $\|x-T x\| \geq f(D(x, F))$ for all $x \in C$, where $D(x, F)=\inf \{\|x-p\|: p \in F=F(S) \cap F(T)\}$.

Theorem 2.5. Let $E$ be a real Banach space and let $C, S, T, F,\left\{x_{n}\right\}$ be as in Theorem 2.1. Then $\left\{x_{n}\right\}$ converges strongly to a point of $F$ if and only if $\liminf _{n \rightarrow \infty} D\left(x_{n}, F\right)=0$.

Proof. Necessity is obvious. Suppose that $\liminf _{n \rightarrow \infty} D\left(x_{n}, F\right)=0$. By Theorem 2.1, $\lim _{n \rightarrow \infty}\left\|x_{n}-w\right\|$ exists for all $w \in F$. Therefore $\lim _{n \rightarrow \infty} D\left(x_{n}, F\right)$ exists. But by hypothesis, $\liminf _{n \rightarrow \infty} D\left(x_{n}, F\right)=0$, therefore we have

$$
\lim _{n \rightarrow \infty} D\left(x_{n}, F\right)=0 \text {. }
$$

Clearly, $\left\{x_{n}\right\}$ is a Cauchy sequence and therefore converges, say, to $q$. Since $\lim _{n \rightarrow \infty} D\left(x_{n}, F\right)=0$, we get $D(q, F)=0$. Consequently, $q \in F$.

Applying Theorem 2.5, we obtain a strong convergence theorem using the scheme (1.6) under the condition $\left(A^{\prime}\right)$ as follows.

Theorem 2.6. Let $E$ be a real Banach space and let $C, S, T, F,\left\{x_{n}\right\}$ be as in Theorem 2.1. Let $S, T$ satisfy the condition $\left(A^{\prime}\right)$ and $F \neq \varnothing$. Then $\left\{x_{n}\right\}$ converges strongly to a point of $F$.

Proof. In Theorem 2.1, we proved that

$$
\lim _{n \rightarrow \infty}\left\|x_{n}-S x_{n}\right\|=0=\lim _{n \rightarrow \infty}\left\|x_{n}-T x_{n}\right\| .
$$

Thus from the condition $\left(A^{\prime}\right)$, we get

$$
\lim _{n \rightarrow \infty} f\left(D\left(x_{n}, F\right)\right) \leq \lim _{n \rightarrow \infty}\left\|x_{n}-T x_{n}\right\|=0
$$

or

$$
\lim _{n \rightarrow \infty} f\left(D\left(x_{n}, F\right)\right) \leq \lim _{n \rightarrow \infty}\left\|x_{n}-S x_{n}\right\|=0 .
$$

In both the cases,

$$
\lim _{n \rightarrow \infty} f\left(D\left(x_{n}, F\right)\right)=0 .
$$

Since $f:[0, \infty) \rightarrow[0, \infty)$ is a nondecreasing function satisfying $f(0)=0$, $f(r)>0$ for all $r \in(0, \infty)$, therefore we have

$$
\lim _{n \rightarrow \infty} D\left(x_{n}, F\right)=0 .
$$

Now all the conditions of Theorem 2.5 are satisfied, therefore by its conclusion $\left\{x_{n}\right\}$ converges strongly to a point of $F$. 
Corollary 2.7. Let $C$ be a nonempty closed convex subset of a uniformly convex Banach space $E$. Let $T$ be a nonexpansive mapping of $C$. Let $\left\{x_{n}\right\}$ be defined by the iteration scheme (1.3) where $\left\{\alpha_{n}\right\},\left\{\beta_{n}\right\}$ are in $[\varepsilon, 1-\varepsilon]$ for all $n \in \mathbb{N}$ and for some $\varepsilon$ in $(0,1)$. If $F(T)$, the set of fixed points of $T$, is nonempty, then $\left\{x_{n}\right\}$ converges strongly to a fixed point of $T$.

Proof. Choose $S=T$ in the above theorem.

Corollary 2.8. Let $C$ be a nonempty closed convex subset of a uniformly convex Banach space E. Let $T$ be a nonexpansive mapping of $C$. Let $\left\{x_{n}\right\}$ be defined by the iteration scheme (1.2) where $\left\{\alpha_{n}\right\}$ is in $[\varepsilon, 1-\varepsilon]$ for all $n \in \mathbb{N}$ and for some $\varepsilon$ in $(0,1)$. If $F(T)$, the set of fixed points of $T$, is nonempty, then $\left\{x_{n}\right\}$ converges strongly to a fixed point of $T$.

Proof. Choose $T=I$ in the above theorem.

Remark 2.9. (i) Corollaries of the above type can also be obtained from Theorems 2.4 and 2.5 .

(ii) Theorems 2.4, 2.5 and 2.6 (and their corresponding corollaries as above) can also be proved using the scheme (1.6) with error terms. The sequence $\left\{x_{n}\right\}$, in this case, is defined by

$$
\left\{\begin{array}{l}
x_{1}=x \in C, \\
x_{n+1}=a_{n} T x_{n}+b_{n} S y_{n}+c_{n} \mu_{n}, \\
y_{n}=a_{n}^{\prime} x_{n}+b_{n}^{\prime} T x_{n}+c_{n}^{\prime} v_{n}, n \in \mathbb{N}
\end{array}\right.
$$

where $\left\{a_{n}\right\},\left\{b_{n}\right\},\left\{c_{n}\right\}\left\{a_{n}^{\prime}\right\},\left\{b_{n}^{\prime}\right\},\left\{c_{n}^{\prime}\right\}$ are sequences in $[0,1]$ with $0<\epsilon \leq$ $a_{n}, a_{n}^{\prime} \leq 1-\epsilon<1, a_{n}+b_{n}+c_{n}=1=a_{n}^{\prime}+b_{n}^{\prime}+c_{n}^{\prime}$ and $\left\{\mu_{n}\right\},\left\{v_{n}\right\}$ are bounded sequences in $C$.

\section{Convergence theorems for nonexpansive nonself mappings}

A subset $C$ of $E$ is called a retract of $E$ if there exists a continuous map $P: E \rightarrow C$ such that $P x=x$ for all $x \in C$. Every closed convex subset of a uniformly convex Banach space is a retract. A map $P: E \rightarrow E$ is said to be a retraction if $P^{2}=P$. It follows that if $P$ is a retraction, then $P y=y$ for all $y$ in the range of $P$.

Suppose that $T, S: C \rightarrow E$ are nonexpansive nonself mappings and $P: E \rightarrow$ $C$ is a nonexpansive retraction. We define $\left\{x_{n}\right\}$ as

$$
\left\{\begin{array}{l}
x_{1}=x \in C, \\
x_{n+1}=P\left(\left(1-\alpha_{n}\right) T x_{n}+\alpha_{n} S y_{n}\right), \\
y_{n}=P\left(\left(1-\beta_{n}\right) x_{n}+\beta_{n} T x_{n}\right), \quad n \in \mathbb{N},
\end{array}\right.
$$

where $\left\{\alpha_{n}\right\}$ and $\left\{\beta_{n}\right\}$ are in $(0,1)$.

Now we outline the proofs of the theorems proved in the previous section for nonexpansive nonself mappings. 
Theorem 3.1. Let $C$ be a nonempty closed convex subset of a uniformly convex Banach space E. Let T, $S: C \rightarrow E$ be two nonexpansive nonself mappings and $P: E \rightarrow C$ a nonexpansive retraction. Let $\left\{x_{n}\right\}$ be defined by the iteration scheme (3.1), where $\left\{\alpha_{n}\right\},\left\{\beta_{n}\right\}$ are in $[\varepsilon, 1-\varepsilon]$ for all $n \in \mathbb{N}$ and for some $\varepsilon$ in $(0,1)$. If $F \neq \varnothing$, then $\lim \left\|x_{n}-q\right\|$ exists and $\lim _{n \rightarrow \infty}\left\|x_{n}-T x_{n}\right\|=0$ $=\lim _{n \rightarrow \infty}\left\|x_{n}-S x_{n}\right\|$.

Proof. Let $q \in F$. Then

$$
\begin{aligned}
\left\|x_{n+1}-q\right\| & =\left\|P\left(\left(1-\alpha_{n}\right) T x_{n}+\alpha_{n} S y_{n}\right)-P q\right\| \\
& \leq\left\|\left(1-\alpha_{n}\right) T x_{n}+\alpha_{n} S y_{n}-q\right\| \\
& \leq\left\|x_{n}-q\right\| .
\end{aligned}
$$

Hence $\lim \left\|x_{n}-q\right\|$ exists. Say it $c$.

Now

$$
\begin{aligned}
\left\|y_{n}-q\right\| & =\left\|P\left(\beta_{n} T x_{n}+\left(1-\beta_{n}\right) x_{n}\right)-P q\right\| \\
& =\left\|\beta_{n}\left(T x_{n}-q\right)+\left(1-\beta_{n}\right)\left(x_{n}-q\right)\right\| \\
& \leq\left\|x_{n}-q\right\|
\end{aligned}
$$

implies that $\lim \sup _{n \rightarrow \infty}\left\|y_{n}-q\right\| \leq c$.

Also from $\left\|T x_{n}-q\right\| \leq\left\|x_{n}-q\right\|$, we get $\limsup _{n \rightarrow \infty}\left\|T x_{n}-q\right\| \leq c$ and similarly $\lim \sup _{n \rightarrow \infty}\left\|S y_{n}-q\right\| \leq c$. It then follows

$$
\lim _{n \rightarrow \infty}\left\|\left(1-\alpha_{n}\right)\left(T x_{n}-q\right)+\alpha_{n}\left(S y_{n}-q\right)\right\|=c .
$$

Thus by Lemma $1.1, \lim _{n \rightarrow \infty}\left\|T x_{n}-S y_{n}\right\|=0$. Now

$$
\begin{aligned}
\left\|x_{n+1}-q\right\| & =\left\|P\left(\left(1-\alpha_{n}\right) T x_{n}+\alpha_{n} S y_{n}-q\right)\right\| \\
& \leq\left\|T x_{n}-q\right\|+\alpha_{n}\left\|T x_{n}-S y_{n}\right\|
\end{aligned}
$$

yields that $c \leq \liminf _{n \rightarrow \infty}\left\|T x_{n}-q\right\|$ so that $\lim _{n \rightarrow \infty}\left\|T x_{n}-q\right\|=c$.

On the lines similar to $(3.2)$, we obtain

$$
\lim _{n \rightarrow \infty}\left\|\left(1-\beta_{n}\right)\left(x_{n}-q\right)+\beta_{n}\left(T x_{n}-q\right)\right\|=c
$$

and, in turn, by Lemma 1.1 that

$$
\lim _{n \rightarrow \infty}\left\|x_{n}-T x_{n}\right\|=0
$$

Similarly, we have,

$$
\lim _{n \rightarrow \infty}\left\|x_{n}-S x_{n}\right\|=0
$$

Lemma 3.2. For any $p_{1}, p_{2} \in F, \lim _{n \rightarrow \infty}\left\|t x_{n}+(1-t) p_{1}-p_{2}\right\|$ exists for all $t \in[0,1]$ under the conditions of Theorem 3.1.

Proof. By Theorem 3.1, $\lim _{n \rightarrow \infty}\left\|x_{n}-p\right\|$ exists for all $p \in F$ and therefore $\left\{x_{n}\right\}$ is bounded. Thus there exists a real number $r>0$ such that $\left\{x_{n}\right\} \subseteq$ 
$D \equiv \overline{B_{r}(0)} \cap C$, so that $D$ is a closed convex nonempty subset of $C$. Define $a_{n}: D \rightarrow D$ as

$$
a_{n}(t)=\left\|t x_{n}+(1-t) p_{1}-p_{2}\right\|
$$

for all $t \in[0,1]$. Then we both $\lim _{n \rightarrow \infty} a_{n}(0)=\left\|p_{1}-p_{2}\right\|$ and $\lim _{n \rightarrow \infty} a_{n}(1)=$ $\lim _{n \rightarrow \infty}\left\|x_{n}-p_{2}\right\|$ exist. Let $t \in(0,1)$. For each $n \in \mathbb{N}$, define a mapping $W_{n}: C \rightarrow C$ by

$$
\begin{aligned}
W_{n} x & =P\left(\left(1-\alpha_{n}\right) T x+\alpha_{n} S V_{n} x\right) \\
V_{n} x & =P\left(\left(1-\beta_{n}\right) x+\beta_{n} T x\right), \quad \forall x \in C .
\end{aligned}
$$

It is easy to verify that

$$
\left\|W_{n} x-W_{n} y\right\| \leq\|x-y\|, \quad \forall x, y \in C .
$$

The rest of the proof follows the lines similar to Lemma 2.2.

The following theorems for nonexpansive nonself mappings can now be proved with appropriate modifications in the proofs of Theorems 2.4,2.5, and 2.6 .

Theorem 3.3. Let $E$ be a uniformly convex Banach space and let $C, T, S$ and $\left\{x_{n}\right\}$ be as in Theorem 3.1. Assume that (a) E satisfies Opial's condition, (b) $E$ has a Fréchet differentiable norm or (c) dual $E^{*}$ of E satisfies Kadec-Klee property. If $F \neq \varnothing$, then $\left\{x_{n}\right\}$ converges weakly to a point of $F$.

Theorem 3.4. Let $E$ be a real Banach space and let $C, S, T, F,\left\{x_{n}\right\}$ be as in Theorem 3.1. Then $\left\{x_{n}\right\}$ converges to a point of $F$ if and only if

$$
\lim \inf _{n \rightarrow \infty} D\left(x_{n}, F\right)=0 \text {, }
$$

where $D(x, F)=\inf \{\|x-p\|: p \in F\}$.

Theorem 3.5. Let $E$ be a real Banach space and let $C, S, T, F,\left\{x_{n}\right\}$ be as in Theorem 3.1. Let $S, T$ satisfy the condition $\left(A^{\prime}\right)$ and $F \neq \varnothing$. Then $\left\{x_{n}\right\}$ converges strongly to a common fixed point of $S$ and $T$.

Remark 3.6. The above theorems can also be proved by using the scheme (3.1) with error terms.

Acknowledgement. This work was supported by Kyungnam University Research Fund, 2008.

\section{References}

[1] M. Abbas, S. H. Khan, and J. K. Kim, A new one-step iterative process for common fixed points in Banach spaces, J. Inequal. Appl. 2008 (2008), Art. ID 548627, 10 pp.

[2] R. P. Agarwal, D. O'Regan, and D. R. Sahu, Iterative construction of fixed points of nearly asymptotically nonexpansive mappings, J. Nonlinear Convex Anal. 8 (2007), no. $1,61-79$.

[3] F. E. Browder, Nonlinear operators and nolinear equations of evolution in Banach spaces, Proc. Symp. Pure Math., Vol. 18, Proc. Amer. Math. Soc., Providence, RI, 1976. 
[4] R. E. Bruck, A simple proof of the mean ergodic theorem for nonlinear contractions in Banach spaces, Israel J. Math. 32 (1979), no. 2-3, 107-116.

[5] G. Das and J. P. Debata, Fixed points of quasinonexpansive mappings, Indian J. Pure Appl. Math. 17 (1986), no. 11, 1263-1269.

[6] H. Fukhar-ud-din and S. H. Khan, Convergence of iterates with errors of asymptotically quasi-nonexpansive mappings and applications, J. Math. Anal. Appl. 328 (2007), no. 2, 821-829.

[7] W. Kaczor, Weak convergence of almost orbits of asymptotically nonexpansive commutative semigroups, J. Math. Anal. Appl. 272 (2002), no. 2, 565-574.

[8] W. Kaczor and S. Prus, Asymptotical smoothness and its applications, Bull. Austral. Math. Soc. 66 (2002), no. 3, 405-418.

[9] S. H. Khan and H. Fukhar-ud-din, Weak and strong convergence of a scheme with errors for two nonexpansive mappings, Nonlinear Anal. 61 (2005), no. 8, 1295-1301.

[10] S. H. Khan and W. Takahashi, Approximating common fixed points of two asymptotically nonexpansive mappings, Sci. Math. Jpn. 53 (2001), no. 1, 143-148.

[11] G. Li and J. K. Kim, Demiclosedness principle and asymptotic behavior for nonexpansive mappings in metric spaces, Appl. Math. Lett. 14 (2001), no. 5, 645-649.

[12] W. R. Mann, Mean value methods in iteration, Proc. Amer. Math. Soc. 4 (1953), 506510 .

[13] Z. Opial, Weak convergence of the sequence of successive approximations for nonexpansive mappings, Bull. Amer. Math. Soc. 73 (1967), 591-597.

[14] J. Schu, Weak and strong convergence to fixed points of asymptotically nonexpansive mappings, Bull. Austral. Math. Soc. 43 (1991), no. 1, 153-159.

[15] N. Shahzad, Approximating fixed points of non-self nonexpansive mappings in Banach spaces, Nonlinear Anal. 61 (2005), no. 6, 1031-1039.

[16] W. Takahashi and G. E. Kim, Approximating fixed points of nonexpansive mappings in Banach spaces, Math. Japon. 48 (1998), no. 1, 1-9.

[17] W. Takahashi and T. Tamura, Convergence theorems for a pair of nonexpansive mappings, J. Convex Anal. 5 (1998), no. 1, 45-56.

[18] Y. Yao and R. Chen, Weak and strong convergence of a modified Mann iteration for asymptotically nonexpansive mappings, Nonlinear Funct. Anal. Appl. 12 (2007), no. 2, $307-315$.

Safeer Hussain KHAN

Department of Mathematics

Statistics AND Physics

QATAR UNIVERSITY

DOHA 2713, QATAR

E-mail address: safeer@qu.edu.qa; safeerhussain5@yahoo.com

JONG KYU KIM

Department of Mathematics

EDUCATION

KYUNGNAM UNIVERSITY

MASAN 631-701, KorEA

E-mail address: jongkyuk@kyungnam.ac.kr 